\title{
Политическая субъектность туристических блогеров и онлайн-сообществ
}

\author{
Чугунова А.A. \\ Санкт-Петербургский государственный электротехнический университет «ЛЭТИ» \\ им. В.И. Ульянова (Ленина), \\ Россия, 197376, г. Санкт-Петербург, ул. Профессора Попова, д. 5 \\ E-mail: aachugunova@etu.ru
}

\begin{abstract}
Аннотация. В статье предлагается интерпретация деятельности туристических онлайн-сообществ как политических субъектов и инструмента «мягкой силы». Обсуждаются результаты эмпирического исследования, полученные при проведении интервью с влиятельными блогерами, пользователями популярных туристических интернет-сайтов, a также контент-анализ комментариев, размещенных на Форуме Винского. Делается заключение о том, что, хотя преждевременно говорить об осознании агентами туристической деятельности в онлайнпространстве степени своего политического влияния и своего места в развитии международного сотрудничества, вместе с тем, действуя аналогично новым медиа, блогеры предстают как лидеры общественного мнения, и деятельность туристических сообществ в интернете можно интерпретировать как форму публичной дипломатии.
\end{abstract}

Ключевые слова: политическая субъектность, блогеры, инфлюэнсеры, «мягкая сила», онлайнпространство, политическая коммуникация, политическое влияние, сетевая коммуникация, туристические сообщества.

Для цитирования: Чугунова А.А. 2021. Политическая субъектность туристических блогеров и онлайн-сообществ. Via in tempore. История. Политология. 48 (3): 724-736. DOI 10.52575/2687-0967-2021-48-3-724-736.

\section{The political subjectivity of travel bloggers and online communities}

\author{
Anna A. Chugunova \\ Saint Petersburg Electrotechnical University «LETI», \\ 5 Professor Popov St., Saint Petersburg, 197376, Russia \\ E-mail: aachugunova@etu.ru
}

\begin{abstract}
The article offers an interpretation of the activities of online travel communities as political subjectivities and a soft power tool. The results of empirical research obtained through interviews with influential bloggers, users of popular travel websites and a content analysis of comments posted in the Vinsky Forum are discussed. The conclusion is drawn that, although it is premature to talk about the awareness of online travel agents of their political influence and their place in the development of international cooperation, nevertheless, acting similarly to new media, bloggers appear as opinion leaders, and the activities of online travel communities can be interpreted as a form of public diplomacy. The purpose of this paper is to investigate the activities of online travel communities as subjects of political influence in the digital environment. The research hypothesis is that specialized forums and social networks for travelers acquire the status of political players in the digital environment, influencing the formation of the image of countries and regions, the decision-making of participants in online travel communities. With online tourist activity is associated the search for new incentives for the development of world economies in a crisis situation: the activities of participants in the tourism business in the most
\end{abstract}


stringent periods of social constraints was fully transferred to the online environment, demonstrating nonstandard methods of solving management problems in a critical period.

Keywords: political subjectivity, bloggers, Influencers, soft power, online space, political communication, political influence, online communication, tourism communities.

For citation: Chugunova A.A. 2021. The political subjectivity of travel bloggers and online communities. Via in tempore. History. Political Science. 48 (3): 724-736 (in Russian). DOI 10.52575/2687-0967-2021-48-3-724-736.

\section{Введение}

Современные путешественники, как правило, активно включаются в коммуникационные процессы на всех стадиях подготовки и реализации своего путешествия. Для этих людей путешествия - не просто отдых, но важная составляющая образа жизни, реализация социальной и жизненной активности. При этом само посещение новых мест включено в более развернутый сценарий путешествия, поскольку эта категория путешественников настроена на то, чтобы оставлять «цифровой след» своего путешествия, а именно вести во время поездки онлайн-репортажи и дневники, составлять подробные отчеты и отзывы о своих передвижениях, делиться опытом и полученной информацией со всеми заинтересованными лицами. Реализуя свою туристическую активность, самостоятельные путешественники наряду с эмоциональной вовлеченностью демонстрируют высокий уровень социальной ответственности и критической самооценки. По существу названные поведенческие характеристики свойственны лидерам мнения. Можно утверждать, что развитие индивидуального, авторского и самостоятельного туризма маркирует становление новых субъектов политического влияния [Чугунова, 2019].

Цель данной работы - проблематизировать деятельность туристических интернетсообществ как субъектов политического влияния в цифровой среде. Исследовательская гипотеза состоит в том, что специализированные форумы и социальные сети для путешественников приобретают статус политических игроков в цифровой среде, влияющие на формирование имиджа стран и регионов, на принятие решений участниками туристических интернет-сообществ. Динамика названных процессов получила мощный импульс в переживаемый человечеством период пандемии COVID-19. Туризм по общей оценке признается наиболее пострадавшей от случившейся эпидемии отраслью. Вместе с тем именно с туризмом, а точнее, с туристической онлайн-активностью связан поиск новых стимулов развития мировых экономик в кризисной ситуации: деятельность участников туристического бизнеса в наиболее строгие периоды социальных ограничений была полностью перенесена в онлайн-среду, демонстрируя нестандартные методы решения управленческих задач в критический период.

\section{Объекты и методы исследования}

Концептуальными ресурсами настоящего исследования выступают понятия политической субъектности, «мягкой силы» и «цифровой власти».

Исследователи проблемы политической субъектности подчеркивают, что, наряду с широко используемыми в современном политическом знании понятиями «политического актора» и «политического агента», сохраняется потребность в концепте «политическая субъектность» с целью раскрытия механизмов, посредством которых человек приобретает качество «политического субъекта» [Шеляпин, 2008; Гнидина, 2010; Першуткин, 2014; Гомеров, 2015], переходит из «потенциального субъектного состояния в актуальное субъектное состояние и/или из одного, менее актуального субъектного состояния, в другое, более актуальное субъектное состояние» [Гомеров, 2015, с. 57]. Выделяя ключевые усло- 
вия становления политической субъектности индивида или группы, Гомеров И.Н., например, называет следующие: участие в реальных процессах политической жизни; осознание собственных политических интересов, прав и обязанностей; политическая самоидентификация; определенный уровень институционально-политической самоорганизации; инициирование политической активности [Гомеров, 2015, с. 59]. Можно вспомнить и высказывание Макса Вебера: «Можно заниматься "политикой“ - то есть стремиться влиять на распределение власти между политическими образованиями и внутри них - как в качестве политика "по случаю“, так и в качестве политика, для которого это побочная или основная профессия, точно так же, как и при экономическом ремесле» [Вебер, 2017, с. 261]. Динамический аспект, входящий в методологическую рамку концептуализации политической субъектности, представляет научную ценность для анализа поставленных в нашей статье вопросов.

Здесь важно отметить, что термин «политика» мы используем в более широком значении, чем отношения с государственной властью, бюрократическим аппаратом и государственными институтами по поводу власти, ее завоевания, удержания и использования в интересах отдельных индвидидов, групп или общества в целом. Тогда как существует еще общественная власть, которая базируется на общественных организациях, общественном мнении, СМИ. И именно наличие этой формы власти изменило характер властных отношений. Наряду с моделями «господство - подчинение» появились отношения типа «руководство - принятие». Важно изменение отношения к политике как к сфере этики отвественности. Но это возможно в первую очередь в рамках развитого Гражданского общества и правового государства, где развивается процесс институализации политической этики и повышается политическая культура населения.

Автор концепции «мягкой силы» Джозеф Най [Най, 2006] в 1971 г. в статье «Транснациональные отношения и мировая политика», написанной вместе с Робертом Кеохэйном, подчеркивал, что государства не являются единственными участниками международных отношений [Nye, Keohane, 1971]. Развивающиеся коммуникационные технологии изменяют полярности силы, стимулируя применение ненасильственных методов для достижения политических целей. «Мягкая сила - это способность оказывать влияние на других через поиск союзников, разработку повестки дня, убеждение, создание притяжения в целях достижения предпочтительного результата» [Nye, 1990, p. 20-21]. Иначе говоря, основными инструментами «мягкой силы» предлагается рассматривать привлекательность и убеждение [Soft power: теория, ресурсы, дискурс, 2015; Лебедева, 2017]. Сферами социальной деятельности, способными оказывать аттрактивное воздействие, признаются брендинг государств, образование, спорт, художественная культура, язык, национальная кухня, а также интересующий нас туризм [Soft Power, мягкая сила, мягкая власть. Междисциплинарный анализ, 2020].

Представление о туризме как инструменте «мягкой силы» завоевывает все большее признание. В «Энциклопедию туризма», выпущенную издательским домом Springer International Publishing в Швейцарии, включен самостоятельный раздел, названный «Soft power, tourism» [Encyclopedia of Tourism, 2015]. Авторы энциклопедической статьи утверждают, что международное влияние страны прямо коррелирует с ее туристической привлекательностью, готовностью вкладывать в нее инвестиции, экспортом продукции, привлечением способных кадров. «Можно выделить, по крайней мере, четыре взаимосвязанных аспекта, позволяющие признать туризм мягкой силой. Во-первых, туристы стремятся как можно больше узнать о выбранной дестинации, что не может не сопровождаться эмоциональной включенностью и стремлением к более тесному общению с населением посещаемого места. Во-вторых, туризм стимулирует работу над формированием привлекательного имиджа страны. Брендинг места назначения тем самым предстает как ресурс «мягкой силы». В-третьих, мега-события, такие как Олимпийские игры, Всемирные выставки, привлекая туристов, реализуют геополитическое влияние организующей эти со- 
бытия страны. В-четвертых, туристы становятся активными информаторами, рассказывая о странах, из которых они возвращаются» [Encyclopedia of Tourism, 2015]. Результаты проведенной нами эмпирической проверки первого и четвертого аспектов, отмеченных в энциклопедии, предложены в настоящей статье.

Методологическую ценность для нашего исследования представляют также активно разрабатываемые в последнее время идеи цифровой власти и «коммуникативного капитализма», согласно которым коммуникативные технологии в Интернет конституируют новых властных субъектов, конкурирующих с традиционными политическими игроками. Поставщики цифровой продукции разного информационного уровня становятся бенефициарами, влиятельными лицами и потому политическими игроками. Потенциально глобальные цифровые игроки любого уровня могут влиять не только на микро-, но и на макропроцессы, становясь модераторами социальных изменений [Кастельс, 2020; Gavra, Dekalov, 2019; Gavra, Dekalov, Naumenko, 2020].

\section{Результаты и их обсуждение}

Проведенное нами эмпирическое исследование включало:

- опрос пользователей петербургского клуба путешественников «ПИК» и общероссийского онлайн-ресурса «Туристер»;

- интервью с Инстаблогерами, специализирующимися на петербургской тематике;

- $\quad$ контент-анализ Форума Винского - интернет-форума самостоятельных путешественников.

\section{Опрос пользователей туристических интернет-сообщесть}

Опрос пользователей петербургского клуба путешественников «ПИК» и общероссийского онлайн-ресурса «Туристер» проводился в ноябре-декабре 2020 г. Выборка определяется как случайная, что соответствует характеру онлайн-исследований. Группа сообщества «Пик» ВКонтакте насчитывает 80 тыс. подписчиков, являясь одним из самых популярных туристических онлайн-ресурсов в данной социальной сети. Наше обращение с просьбой принять участие в опросе получило 7,5 тыс. просмотров и 2 репоста ${ }^{174}$. Ответили на анкету 38 человек. Наш опрос в социальной сети для туристов «Туристере» проводился в теме на форуме, которую указали администраторы. Всего в ноябре 2020 г. статистика просмотров сайта составила 6300 , зафиксировано 965 показов темы с опросом, 41 комментарий, на вопросы анкеты ответили 67 пользователей. Таким образом, общее количество ответов составило 105, а количество просмотров без реакции для нас также являлись результатом (показатель незаинтересованности данной темой, нежелание участвовать в исследовании). Однако полученные ответы позволяют говорить о репрезентативности результатов, так как, во-первых, участвовали именно самостоятельные путешественники, что наиболее интересно с точки зрения указанных в методологии концепций. А с другой, заложенные в анкеты открытые вопросы позволяют получить развернутые комментарии, оценки, увидеть трактовки.

Туристическое сообщество «Пик» существует с 2007 г., базируется в СанктПетербурге, в 2020 г. насчитывало 155 инструкторов и 80 работников смежных областей. До периода пандемии туристический клуб выступал организатором походов в различные регионы России и за рубеж, обслуживая более 7 тысяч человек в год. Миссионерской особенностью сообщества выступает экологический туризм, включая уборку мусора в местах отдыха, а также развитие проекта «Экокодекс».

174 Пост с просьбой принять участие в опросе. - URL: https://vk.com/wall-7107168_83410 (дата обращения: 20.07.2021). 
Содержание анкеты включало следующие тематические блоки: типы поездок, мотивация туристических поездок, наличие взаимодействия и готовность к установлению контактов, информирование о России в ходе поездки, отношение к России в дестинации, социальная активность в туристических онлайн-сообществах.

Мы исходили из исследовательского допущения о том, что среди подписчиков сообщества «Пик» преобладают активные самостоятельные путешественники, часто выезжающие за рубеж, с выраженной ответственностью за свою туристическую активность и создаваемый образ своей страны. Результаты опроса подтвердили наши ожидания лишь частично.

Среди респондентов действительно доминировали самостоятельные путешественники: при организации своих путешествий 92,1\% не пользуются услугами туристических фирм или делают это редко. Однако ожидание, что на решение о поездке влияет информация, полученная от блогеров или на сайтах онлайн-сообществ, не подтвердилось: доминирующими мотиваторами поездок оказались выгодные предложения от транспортных компаний или мест размещения, фотографии и реклама, размещенные в разнообразных СМИ. 84,1\% туристов активно знакомятся с местными жителями во время путешествий, однако лишь половина $(44,6 \%)$ затем поддерживают знакомство перепиской. 78,8 \% охотно рассказывают о своей стране или отвечают на вопросы, если к стране проявляют интерес. Часть путешественников обязательно запасаются в дорогу сувенирами. Однако на вопрос «Разделяете ли вы мнение, что турист за границей должен создавать привлекательный образ своей страны? » 16 \% ответили, что вовсе не задумываются об том. Еще меньше опрошенных - 10,5\% - ассоциируют туризм с «народной дипломатией» и целенаправленным созданием имиджа страны. 18 \% предпочли не смешивать туризм и политику. Впрочем, более половины согласились с тем, что любой турист, независимо от своего желания, своим поведением формирует представление о своей стране.

Отвечая на вопросы об отношении к ним жителей дестинации, лишь 4 \% отметили негативное поведение, доминирующим они считают благожелательный настрой, заложенный в саму модель отношений «клиент - продавец».

На вопрос «Оставляете ли $\mathrm{Bbl} \mathrm{отзыв} \mathrm{или} \mathrm{отчет} \mathrm{о} \mathrm{поездке} \mathrm{в} \mathrm{сети?»} 75$ \% ответили, что делают это постоянно или время от времени, в том числе $50 \%$ делают это в социальных сетях, $25 \%$ - в онлайн-сообществах или на сайтах бронирования. Каждый четвертый указал, что рассказывает о поездке только друзьям или родственникам или вообще избегает разговоров о поездках.

Отметим, что, будучи активными самостоятельными путешественниками, респонденты группы сообщества «Пик» ВКонтакте не связывают свою активность с принадлежностью к онлайн-сообществу и не очень высоко оценивают его влияние на свою деятельность.

Сайт Туристер.ру - один из крупнейших в русскоязычном интернет-пространстве, объединяющий опытных путешественников. На конец ноября 2020 г. он насчитывал почти 348 тыс. зарегистрированных пользователей. Это хорошо организованная информационная площадка самостоятельных путешественников, включающая разделы со списком посещенных стран и городов с отображением на интерактивной карте, возможностью оставлять личные сообщения и комментарии, советы путешественникам, отзывы и мнения о городах, странах и достопримечательностях, фотоальбомы. Организаторы проекта приветствуют любую деятельность, связанную с обменом туристическим опытом. «Туристер» позиционирует себя (и, согласно опросу, фактически является) классическим онлайнсообществом, объединяющим людей, для которых важнейшей ценностью являются туризм и путешествия. Как и в случае с сообществом «Пик», основные пользователи сайта это самостоятельные путешественники: 91,1\% либо не обращаются к туристическим фирмам при подготовке своей поездки, либо делают это крайне редко. Участники сообщества оказались лояльной аудиторией своего портала. 23,9 \% указали материалы сообще- 
ства «Туристер» как вдохновляющий фактор при планировании новых поездок. «Туристер» получил и наивысшую отметку в оценке своей деятельности среди других онлайнсообществ, причем со значительным отрывом, например, от Форума Винского. Большинство участников опроса предпочитают оставлять отзывы или отчеты именно на данном портале. В ответах на открытые вопросы респонденты подчеркивали такие преимущества сайта, как «богатый материал для ознакомления», обмен опытом, советы, эксклюзивная информация и др.

Отвечая на вопрос «Появляются ли в результате поездки у Вас знакомые в других cтранах/регионах?», участники «Туристера» демонстрировали активность в общении и установлении новых контактов. В то же время статистика ответов на вопрос: «Оказываясь в другой стране, Вы рассказываете о России своим новым знакомым?» оказалась почти на $10 \%$ ниже, чем в группе «Пик». $15 \%$ согласились с утверждением «Путешествуя по другой стране, я не задумываюсь, что я - представитель своей страны или своего региона за границей», за исключением представителей Белоруссии и Израиля, подчеркнувшими, что они всячески стараются нести ценности своих стран.

Сходными с «Пиком» оказались и ответы на вопрос «Разделяете ли вы мнение, что турист за гранищей должен создавать привлекательный образ своей страны?»: половина респондентов считает, что «турист неизбежно создает представление о своей стране уже своим поведением, не затрачивая специальных усилий». Процент тех, кто указал, что «туризм должен быть вне политики», оказался выше, чем среди пользователей «Пика»: 25 \% против $18 \%$.

В ответах на вопрос «Опираясь на собственный опыт путешествий, как Вы оцениваете отношение к российским туристам в принимающей стране?» большинство респондентов подтвердили, что отношение зависит от поведения туриста, а также определяется «экономическим фактором» (турист = заказчик услуг).

Заметное различие в поведении пользователей рассматриваемых ресурсов обнаруживается после путешествия: среди тех, кто не считает нужным оставлять отзыв, пользователей «Туристера»- $3 \%$, тогда как «Пика» - $21 \%$, и $45 \%$ против $21 \%$ среди тех, кто оставляет отзыв обязательно. Одним из объяснений этого различия может быть то, что сама площадка онлайн-сообщества располагает к подробным отчетам о поездке (мотивируют другие участники благодаря наличию функции обратной связи), тогда как в группе «Пик» такой функции нет.

Информационную ценность для нас имели ответы на вопросы о привлекательности туристических интернет-сообществ, поскольку содержали данные о формах коммуникативной активности их пользователей. Иерархически преимущества онлайн-сообществ распределились следующим образом: наиболее значимым оказался фактор «клуба по интересам», возможность получить совет, поделиться опытом, пообщаться, вдохновиться; меньшее число респондентов отметили информативную ценность площадок. Среди отдельных высказываний отметим следующие: «Сейчас преимуществ уже нет. Эти сообщества теряют свое значение», «У всех свои плюсы и минусы». Мнение иностранного участника сообщества: «Online community allows you to find people of similar interests and background. It helps to shape your travel ideas and form expectations based on reviews by people close to you in terms of culture, income and social status».

\section{Интервью с блогерами}

При формировании выборки блогеров для проведения интервью мы руководствовались следующими условиями: 
1) их деятельность на площадке Instagram как наиболее активной по числу авторов в России ${ }^{175}$;

2) специализация на петербургской тематике;

3) число подписчиков не менее 5 тыс. человек с высокой вовлеченностью читателей (более 500 лайков в среднем под каждым из постов, активное комментирование, а также наличие ответов от автора страницы).

Из 13 отобранных нами респондентов, соответствующих описанным условиям, интервью согласились дать 4 человека. Каждый из них - создатель страницы в Инстаграме с количеством подписчиков от 6,8 до 40,9 тыс. Трое из четверых имели опыт работы профессиональными гидами или экскурсоводами-любителями, проводящими авторские экскурсии. Все четверо с высшим образованием: политолог, культуролог, специалист по связям с общественностью, педагог. Время создания блогов - между 2014 и 2019 гг., основная читательская аудитория одного из респондентов - жители Санкт-Петербурга, подписчики остальных - гости города или те, кто хотел бы посетить Петербург. Все четверо ведут свой блог самостоятельно, для двоих в настоящее время ведение блога является составной частью основной работы, для двух других - второй работой или хобби. Определяя миссию своих страниц, наши респонденты сформулировали ее как желание показать Петербург в деталях, раскрыть неизвестные стороны городской жизни, открыть петербуржцам и гостям города новые интересные места. Хотя все выбранные блоги были тематически связаны с Петербургом, их целевые аудитории различались. Так, блог, ориентированный на петербуржцев, формирует атмосферу принадлежности к местному сообществу, что, впрочем, может оказывать влияние на иностранную и иногороднюю аудитории.

В содержании интервью получили отражение как различие числа подписчиков (от 7 до 41 тыс.), так и опыт ведения страницы (от 2 до 6 лет). Очевидно, что число подписчиков от 15 тыс. человек и более требует от автора блога дополнительных методов раскрутки, денежных вложений в рекламу и др. Иначе говоря, по трудозатратам он превращается в профессиональную деятельность, требующую мотивации, эмоциональной подпитки, своевременного отдыха во избежание выгорания. Совмещать его с другой работой становится затруднительным.

Проверяя гипотезу о политическом влиянии блогеров, мы получили подтверждение, что они действительно оказывают серьезное влияние на принятие решений их подписчиками, потенциальными туристами из других стран, на создаваемый образ страны и/или города. Многие приводили примеры того, как после публикации их материалов у людей появлялось желание посетить Петербург или даже переехать в него жить. Все наши эксперты поддерживают хороший контакт со своей аудиторией, лично реагируют на комментарии, вопросы и сообщения. Отметим также, что если два респондента придерживаются так называемой симметричной модели коммуникации, то есть стремятся реагировать на предложения своих читателей, проводят опросы и вводят новые темы и рубрики, то два других так еще не делают или уже не делают. Для троих влияние на аудиторию не исчерпывается только блогом, их основная работа с подписчиками происходит на экскурсиях, тем самым блог оказывается дополнительным инструментов профессиональной коммуникации.

Раздел интервью, проверяющий гипотезу о формировании блогерами общественного мнения своей аудитории, стал показательным. Два респондента из четырех усомнились в степени своего политического влияния. Лишь одна из четверых (по образованию специалист по связям с общественностью) признала свой статус инфлюенсера. Еще одна респондентка (политолог по образованию) знала содержание понятия «мягкая сила» и возможность его применения к своей деятельности. Остальные предпочитали не рассмат-

175 Согласно данным исследования «Социальные сети в России: цифры и тренды, осень 2020». URL: https://br-analytics.ru/blog/social-media-russia-2020 (дата обращения: 21.07.2021). 
ривать свою деятельность как политическую. При этом всех наших интервьюируемых можно охарактеризовать как социально-ответственных представителей интернетсообщества: они осознают свои миссии, не стремятся к саморекламе, не провоцируют конфликты, не формируют негативный образ Санкт-Петербурга, если и показывают неприглядные стороны города, то сопровождая поиском причин. Все наши респонденты отмечали важность дополнения онлайн-деятельности офлайн-активностями - коллаборациями, встречами с подписчиками, участием в блог-турах, в создании туристических маршрутов. Одна из информанток отметила, что именно представители блогерского сообщества вышли с предложением к городскому комитету по туризму о включении блогеров в проводимые городской администрацией мероприятия и презентации ${ }^{176}$.

Проверяя оценку нашими информантами деятельности туристических онлайнсообществ, мы обнаружили то, что можно назвать «информационной немотой», то есть отсутствие желания обсуждать этот вопрос. Отчасти это может свидетельствовать о падении интереса и доверия к таким массовым площадкам, как Форум Винского, TripAdvisor (один из респондентов заметил: «На трипэдвайзоре, к сожалению, стало много заказных отзывов, в особенности негативных»), смещении фокуса к социальным сетям. Приведем еще отрывок из интервью: «Многие люди переходят в соцсети - в тот же инстаграм, в телеграм. Человек хочет получить личную рекомендацию... Хорошо развиваться и там, и там. Например, когда началась пандемия, петербургские гиды первыми в России стали проводить онлайн-экскурсии, реклама шла сначала на страничках, только потом подтянулись онлайн-площадки». Замеченный нами феномен можно объяснить ценностью для блогеров личного бренда и репутации инфлюенсеров в том же инстаграме. Они приложили немало усилий, чтобы собрать лояльных подписчиков, завоевать их доверие, используют авторский контент, борются с плагиатом, и потому не могут поставить под угрозу свою репутацию из-за недостоверной рекламы, непроверенной информации или вмешательства сторонних специалистов в их деятельность. Общаясь со своей аудиторией, они не позволяют себе некорректное поведение, в то время как на массовых площадках и форумах можно встретить оскорбительные комментарии, скрытые за безликими никами и аватарками.

Из интервью: «Я считаю, что онлайн-сообщества во многом формируют привычки, поведение туристов. Не могу говорить о старшем поколении, но мы (я и мои сверстники), когда планируем путешествие, обязательно ищем информацию в социальных сетях, в т. ч. по геометкам той локации, куда едем. И благодаря рекомендациям в инстаграме и другим рекомендациям мы выбираем места, что хотим посетить. Если они вызывают доверие, то, конечно, к ним прислушиваются. Такие сообщества актуальны и полезны».

Все респонденты, будучи организаторами экскурсий, отмечали рост индивидуального, интеллектуального, авторского туризма. Путешественники едут подготовленными, начитанными, с четкими представлениями, что хотели бы увидеть, многие готовят основную программу путешествий самостоятельно. К специалистам такие путешественники обращаются, желая познакомиться с малоизвестными сторонами жизни города, его эмоциональной атмосферой, труднодоступной гостям и приезжим.

На вопрос «Вдохновляют ли Вас ваши подписчики на создание новых постов о Петербурге?» все респонденты единодушно согласились. Приведем несколько высказываний из интервью:

«Обратная связь - это очень важно! Люди мотивируют творить! Так как за три года уже можно было исписать все, поэтому я время от времени устраиваю опрос, о чем еще рассказать, что хотят почитать?»

176 Популярные travel-блогеры, фотографы и журналисты смогут увидеть Петербург с новой стороны. - 24/11/2020. - URL: https://www.gov.spb.ru/gov/otrasl/c_tourism/news/201735/ (дата обращения: 21.07.2021) 
«Конечно! Я внимательно анализирую и сама всем отвечаю, как уже говорила, провожу опросы. Сильно питают такие истории, когда люди поменяли свое мнение о городе, расстались со стереотипами, благодарности и признания».

«Обратная связь очень важна. Мы, по сути, работаем для зрителей, для лайков (как показатель одобрения), приятны добрые слова благодарности за то, что сохраняем Петербург. Это подпитывает».

«Когда я писала только про Питер, подписчики очень вдохновляли. Я тогда была влюблена в Петербург, считала лучшим городом на земле. Постепенно, когда я увидела другие страны и города, мое мнение стало не таким однозначным. Я хочу писать только о том, что волнует меня, не хочется больше писать о том, что неинтересно, поэтому уже не так зависима от мнения подписчиков».

\section{Контент-анализ Форума Винского}

Форум Винского - один из первых российских ресурсов для самостоятельных путешественников. Уже более 10 лет на нем выкладывают отчеты о путешествиях, делятся советами, пишут отзывы или просто просматривают информацию 80-90 тысяч пользователей в месяц (данные до пандемии 2019 г.). Их привлекает возможность общения в огромном сообществе путешественников, поиск эксклюзивной информации и стремление поделиться опытом или перенять его. Нами был проведен контент-анализ материалов данной площадки в ветке форума, посвященной обсуждению вопросов, связанных с посещением Санкт-Петербурга ${ }^{177}$.

Как видно на рисунке, начиная с 2019 г. посещаемость форума снижается, когда был зафиксирован пик на отметке более чем 100 тыс. читателей в день. К марту-апрелю 2020 г. форум почти опустел.

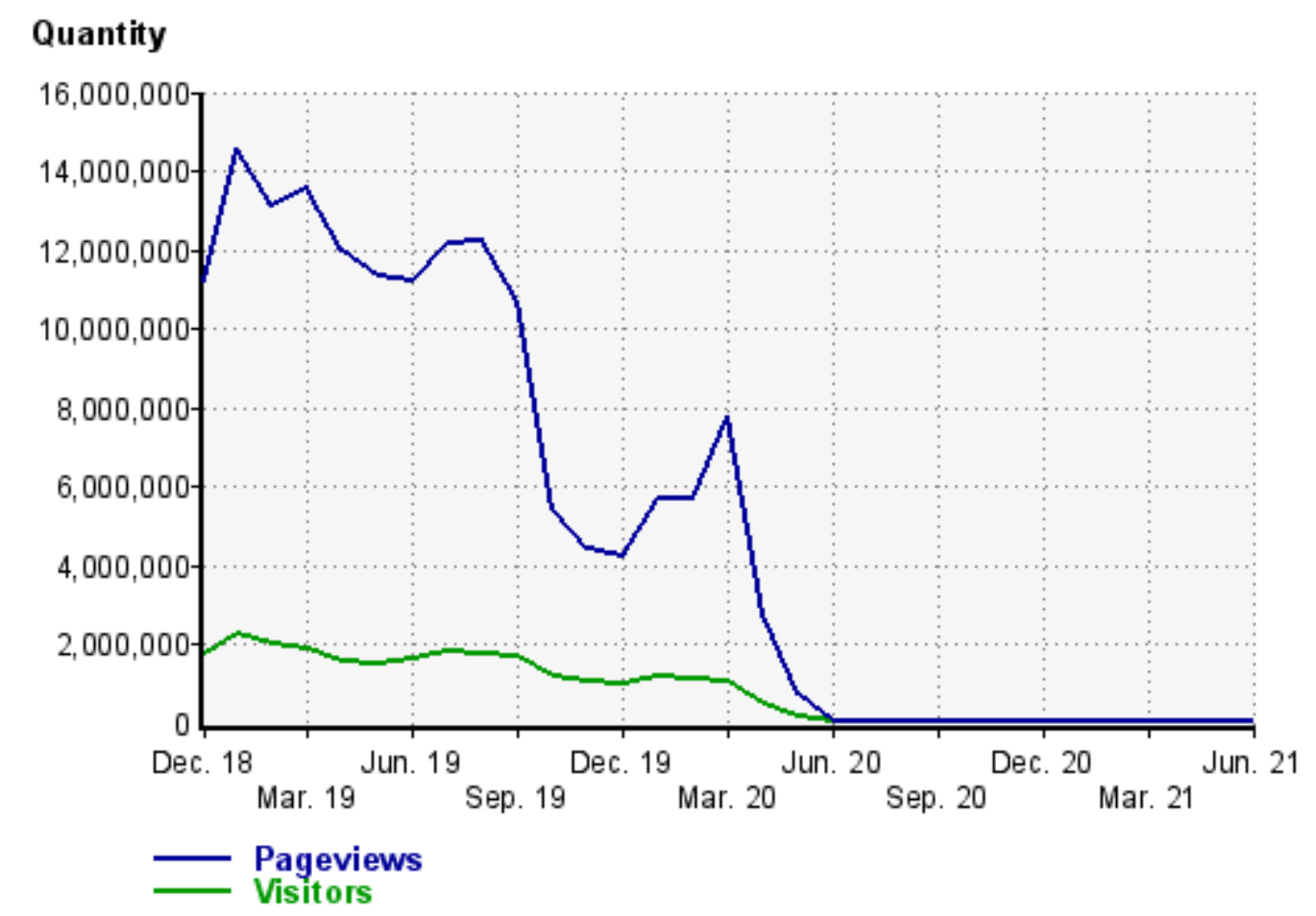

График количества посетителей форума и просмотров страниц в 2019-2021 гг.

The number of forum visitors and page views in 2019-2021

177 Ветка обсуждений по Петербургу. - URL: https://forum.awd.ru/viewforum.php?f=1597 (дата обращения: 21.07.2021). 
Всего было проанализировано 41 сообщение за 2020-2021 гг. Из 26 тем, посвященных Санкт-Петербургу, в 2020 г. было проведено обсуждение по 4 темам.

Были выделены следующие категории контент-анализа:

- характеристики форума: мотивы публикации постов/комментариев, оценка персоны С. Винского, оценка форума, упоминание/сравнение с другими сетевыми площадками;

- $\quad$ имидж Петербурга: позитивные и негативные упоминания.

К результатам контент-анализа, представляющим ценность для проверки нашей исследовательской гипотезы, можно отнести следующие.

1. Низкая активность в обсуждении петербургской тематики. Возможно, это объясняется тем, что для русскоязычных туристов информацию о Санкт-Петербурге не сложно найти в сети и потому нет необходимости делать запрос или советоваться на Форуме. Другой причиной может быть то, что Форум изначально создавался для обсуждения путешествий в другие, в особенности экзотические страны.

2. Не подтвердилась оценка комментариев на Форуме как недружелюбных к посетителям. Незначительные в общем числе негативные комментарии можно объяснить консервативностью среды пользователей Форума, не принимающей новичков. На вопросы, заданные бывалыми участниками Форума, негативная реакция отсутствует. Сам функционал площадки выстраивает определенную иерархию: в информации о каждом пользователе указывается дата регистрации на площадке, количество сообщений, благодарностей, количество стран (от этой цифры присваивается ранг - «новичок», «старожил», «почетный путешественник» и др.), социально-демографические характеристики (пол, возраст, город проживания).

3) Используемый в разных тематических ветках Форума коммуникационный стиль сходен: в своем большинстве ответы на вопросы пользователей излагаются коротко, по существу, иногда на грани вежливости и раздражения. Могут вспыхивать небольшие споры или даже ссоры. Стиль общения задает создатель и главный руководитель Форума - Сергей Винский. Приведем ссылки на два его недавних объявления, выставленных для всех участников. Фейковые и нарисованные ПЦР-тесты - официальная позиция Винского» 11.01.21 ${ }^{178}$ или «Как сейчас попасть в Европу. Тезисно и кратко» 01.03.2021 ${ }^{179}$. Эмоциональная подача информации выполнена хлестко и авторитарно.

\section{Заключение}

Таким образом, эмпирическая проверка гипотезы, что туристические онлайнсообщества и блогеры создают новое политическое интернет-пространство, создает основание для интерпретации их деятельности с использованием понятия «мягкой силы». Активность индивидуальных путешественников и блогеров раскрывает их как агентов политического влияния. Функционально блогеры действуют аналогично новым медиа: регулярно и методично готовят авторский контент для конкретных рубрик, вырабатывают особый стиль подачи материалов (текстовых и визуальных), строго следуя выбранной тематике, фильтруют «неформатные» сообщения, в особенности рекламного характера, уделяют особое внимание оформлению страницы, активно следят за реакцией и предложениями читателей, откликаются на события и новую информацию. Их статус влиятельных акторов подтверждается не только постоянным увеличением числа

\footnotetext{
178 Пример объяления руководителя Форума. https://vk.com/away.php?to=http \%3A \%2F \%2Fforum.awd.ru \%2Fviewtopic.php \%3Ff \%3D613 \%26t \%3D39720 8 (дата обращения: 21.07.2021).

${ }^{179}$ Пример объяления руководителя Форума.

https://forum.awd.ru/viewtopic.php?f=613\&t=398497 (дата обращения: 21.07.2021).
} 
подписчиков, но и приглашениями в блогерские туры, на презентации и мероприятия, организованные городскими туристическими службами, вниманием со стороны других блогеров и представителей СМИ. И хотя в своих интервью наши респонденты не всегда признают свою влиятельность, можно утверждать, что они действуют как лидеры общественного мнения. Анализ проведенного опроса пользователей туристических сайтов раскрывает принципы взаимодействия между сетевыми акторами: они не представляют собой сплоченного сообщества, динамика передвижения пользователей из одной сети в другую очень высока. Вместе с тем именно инфлюенсеры выступают точками «стягивания» пользователей. И хотя пока преждевременно говорить о политической самоидентификации цифровых акторов, осознании ими степени своего политического влияния и понимании своего места в развитии международного сотрудничества, деятельность туристических сообществ в интернет, на наш взгляд, можно интерпретировать как форму народной, или публичной, дипломатии.

\section{Благодарности}

Автор выражает глубокую благодарность научному руководителю, кандидату философских наук, доценту Казариновой Н.В., руководителю ООО «Турклуб ПИК» Афанасьеву В.В.

\section{Список литературы}

1. Вебер М. 2017. Власть и политика. М., Рипол Классик, 432 с.

2. Гнидина Ю.А. 2010. Субъектность личности как условие развития государства и гражданского общества. Балашиха, Ин-т социально-экономического прогнозирования и моделирования, Де-По, 192 с.

3. Гомеров И.Н. 2011. Политическая субъектность в структуре политических отношений: теория и российские реалии. Новосибирск, Новосиб. гос. ун-т, 885 с.

4. Гомеров И.Н. 2015. Субъект как смысловое ядро политической субъектности. Развитие территорий, 3: 51-62.

5. Кастельс М. 2020. Власть коммуникации. Пер. с англ. Под науч. ред. А.И. Черных. М., Изд. дом ВШЭ, 564 с.

6. Лебедева М.М. 2017. «Мягкая сила»: понятие и подходы. Вестник МГИМОУниверситета. 3 (54): C. 212-223. DOI: 10.24833/2071-8160-2017-3-54-212-223.

7. Най Джозеф С. 2006. Гибкая власть: как добиться успеха в мировой политике; перевод В.И. Супруна. Новосибирск, М., Фонд Социо-прогностических исследований «Тренды», 221 с.

8. Soft Power, мягкая сила, мягкая власть. Междисциплинарный анализ: коллектив. монография. 2020. 4-е изд. Под ред. Е.Г. Борисовой. М., ФЛИНТА, 184 с.

9. Soft power: теория, ресурсы, дискурс. 2015. Под ред. О.Ф. Русаковой. Екатеринбург, Издательский Дом «Дискурс-Пи», 376 с.

10. Першуткин С.Н. 2014. Субъект и субъектность в контексте политических коммуникаций. Коммуникология: теория и методология, 3: 79-93.

11. Чугунова А.А. 2019. Турист как СМИ: новый вызов профессиональным коммуникаторам в цифровую эпоху. Сборник XVI Всероссийской научной конференции «ИНФОРМАЦИЯ - КОММУНИКАЦИЯ - ОБЩЕСТВО». СПб: ЛЭТИ, 383-389.

12. Шеляпин Ф.И. 2008. Политическая субъектность в современном политическом развитии: теоретико-концептуальный характер : автореф. дис. ... канд. полит. наук: 23.00.01. М., $30 \mathrm{c}$.

13. Gavra D., Dekalov V., Naumenko K. 2020. Digital Subjects as New Power Actors: A Critical View on Political, Media-, and Digital Spaces Intersection. In: Kotenko I., Badica C., Desnitsky V., El Baz D., Ivanovic M. (eds) Intelligent Distributed Computing XIII. IDC 2019. Studies in Computational Intelligence, vol 868. Springer, Cham. https://doi.org/10.1007/978-3-030-32258-8_28.

14. Gavra D., Dekalov V. 2019. Networked Society and its New Power Actors: Critical Analysis of Hardware, Software, and Communicative Level of Digital Space. IEEE Communication 
Strategies in Digital Society Seminar, ComSDS. Institute of Electrical and Electronics Engineers Inc.: $70-75$.

15. Jafari J., Xiao H. (eds.). 2015. Encyclopedia of Tourism. Springer International Publishing Switzerland. DOI 10.1007/978-3-319-01669-6_184-1.

16. Nye Joseph S., Keohane Robert O. 1971. Transnational Relations and World Politics: An Introduction. International Organization, vol. 25, no. 3, JSTOR: 329-349.

17. Nye Joseph S. 1990. Bound To Lead: The Changing Nature Of American Power. Basic Books, 307 p.

\section{References}

1. Veber M. 2017. Vlast I politika [Power and Politics]. M., Ripol Klassic, 432 p.

2. Gnidina J.A. 2010. Subektnost lichnosti kak uslovie razvitija gosudarstva i grazhdanskogo obshhestva [Personality subjectivity as a condition for the development of the state and civil society]. Balashikha, Institut Socialnojekonomicheskogo prognozirovanija i modelirovanija De-Po, 192 p.

3. Gomerov I.N. 2011. Politicheskaja subektnost v strukture politicheskih otnoshenij teorija i rossijskie realii novosibirsk [Political subjectness in the structure of political relations: theory and Russian realities]. Novosibirsk, Novosibirsk State University, 885 p.

4. Gomerov I.N. 2015. Subekt kak smyslovoe jadro politicheskoj subektnosti [Subject as the sustained kingdom of political subjectivity]. Razvitie territorij, 3. P. 51-62.

5. Castells M. 2009. Vlast' kommunikacii [Communication power]. New York, Oxford University Press, $571 \mathrm{p}$.

6. Lebedeva M.M. 2017. «Myagkaya sila»: ponyatie i podhody [«Soft power»: concept and approaches]. MGIMO Review of International Relations. 3 (54): P. 212-223. DOI: 10.24833/2071-81602017-3-54-212-223.

7. Nai Dzhozef S. 2006. Gibkaya vlast': kak dobit'sya uspekha v mirovoi politike [Bound To Lead: The Changing Nature Of American Power]; perevod V.I. Supruna. Novosibirsk, M., Fond Sotsioprognosticheskikh issledovanii «Trendy». $221 \mathrm{p}$.

8. Soft Power, myagkaya sila, myagkaya vlast'. Mezhdisciplinarnyj analiz [Soft Power, Soft Strength, Soft Authority. Interdisciplinary analysis]. 4th ed. 2020. Ed. by E.G. Borisova. Moscow: FLINTA, $184 \mathrm{p}$.

9. Soft power: teoriya, resursy, diskurs [Soft power: theory, resources, discourse]. 2015. Ed. by O.F. Rusakova. Yekaterinburg: Publishing House «Discourse-PI», 376 p.

10. Pershutkin S.N. 2014. Subekt i subektnost v kontekste politicheskih kommunikacij [Subject and Subjectivity in the Context of Political Communications]. Kommunikologija teorija i metodologija, 3. P. 79-93.

11. Chugunova A.A. 2019. Turist kak SMI: novyj vyzov professionalnym kommunikatoram v cifrovuju jepohu [Travellers as a new media: a new challenge to professional communicators in a digital epoch]. Conference proceedings Information-Communication-Society. Saint Petersburg Electrotechnical University «LETI»: 383-389.

12. Shelyapin F.I. 2008. Politicheskaja subektnost v sovremennom politicheskom razvitii teoretikokonceptualnyj harakter [Political subjectivity in modern political development: theoretical and conceptual character]: autoref. dissertation. Candidate of political sciences: 23.00.01. Moscow. P. 30.

13. Gavra D., Dekalov V., Naumenko K. 2020. Digital Subjects as New Power Actors: A Critical View on Political, Media-, and Digital Spaces Intersection. In: Kotenko I., Badica C., Desnitsky V., El Baz D., Ivanovic M. (eds) Intelligent Distributed Computing XIII. IDC 2019. Studies in Computational Intelligence, vol 868. Springer, Cham. https://doi.org/10.1007/978-3-030-32258-8_28.

14. Gavra D., Dekalov V. 2019. Networked Society and its New Power Actors: Critical Analysis of Hardware, Software, and Communicative Level of Digital Space. IEEE Communication Strategies in Digital Society Seminar, ComSDS. Institute of Electrical and Electronics Engineers Inc.: 70-75.

15. Jafari J., Xiao H. (eds.). 2015. Encyclopedia of Tourism. Springer International Publishing Switzerland. DOI 10.1007/978-3-319-01669-6_184-1.

16. Nye Joseph S., Keohane Robert O. 1971. Transnational Relations and World Politics: An Introduction. International Organization, vol. 25, no. 3, JSTOR: 329-349.

17. Nye Joseph S. 1990. Bound To Lead: The Changing Nature Of American Power. Basic Books, 307 p. 
Конфликт интересов: о потенциальном конфликте интересов не сообщалось.

Conflict of interest: no potential conflict of interest related to this article was reported.

\section{ИНФОРМАЦИЯ ОБ АВТОРЕ}

Чугунова Анна Алексеевна, аспирант кафедры социологии и политологии Санкт-Петербургского государственного электротехнического университета «ЛЭТИ» им. В.И. Ульянова (Ленина), г. Санкт-Петербург, Россия

\section{INFORMATION ABOUT THE AUTHOR}

Anna A. Chugunova, postgraduate at the Department of Sociology and Political Science, Saint Petersburg Electrotechnical University «LETI», St. Petersburg, Russia 